\title{
Polymer electrolytes based on Novel Poly(Ethyl Methacrylate-co-Deproteinized Natural Rubber) for dye sensitized solar cell application
}

\author{
N.F. Zain ${ }^{1 .}{ }^{*}$, N.A. Dzulkurnain ${ }^{2, \dagger}$, A. Ahmad ${ }^{2}$, F. Salleh ${ }^{1}$ and N.S. Mohamed ${ }^{3}$ \\ ${ }^{1}$ Department of Electrical Engineering, Faculty of Engineering, University of Malaya, 50603 Kuala Lumpur, Malaysia \\ ${ }^{2}$ School of Chemical Sciences and Food Technology, Faculty of Science \& Technology, Universiti Kebangsaan Malaysia, 43600 Bangi, Selangor, \\ Malaysia \\ ${ }^{3}$ Centre for Foundation Studies in Science, University of Malaya, 50603 Kuala Lumpur, Malaysia
}

Corresponding Author Email: : *fatinmuhdzain@gmail.com; †nurulakmaliah86@gmail.com

\begin{abstract}
Novel copolymer of ethyl methacrylate - deproteinized natural rubber was prepared by solvent-free UV-curing technique and used as a host in solid polymer electrolytes. For the preparation of polymer electrolytes, magnesium iodide was used as the doping salt. The interaction occurred between polymer and magnesium iodide ions was confirmed by Fourier transform infrared analysis. Thermogravimetric analysis showed that degradation temperature decreased upon addition of magnesium iodide salt. The ionic transport number measurement gave a value of 0.93 confirming that the sample was an ionic conductor. The cationic transport number was found to be 0.04 indicating iodide anions were the main conducting species. The dye sensitized solar cell employing this new copolymer based electrolytes showed reasonably good photoelectrochemical conversion efficiency.
\end{abstract}

Keywords: $P(E M A-c o-D P N R)$, copolymer, magnesium iodide, DSSC

Received: January-21-2018, Accepted: February-19-2018, https://doi.org/10.14447/jnmes.v22i2.a01

\section{INTRODUCTION}

Dye-sensitized solar cells (DSSCs) have attracted much attention since the first report written by O' Regan and Grätzel [1] in 1991 due to their simple preparation procedure, low-cost, environmental compatibility and good performance under diffuse light conditions. To date, the highest solar cell efficiency has reached $13 \%$ [2-3] using liquid electrolytes. However, liquid electolytes possess challenges for practical applications such as leakage and volatilization, packaging problem and toxicity [3-4].

To overcome these shortages, solid polymer electrolytes (SPEs) have been investigated. These SPEs render various advantages including excellent film-forming property, high thermal stability, light weight and easy to handle for device fabrication [5-7]. In spite of their advantages, problems such as low room temperature ionic conductivity [8-9] and poor interfacial electron recombination [10], hinders the DSSCs efficiency.

In order to improve the ionic conductivity of SPEs, modifying the polymer host is one of the alternative approaches, which in turn, would improve the device performance. One of the methods to modify polymer hosts is by using the photo-polymerization technique [11-14]. This technique is a solvent-free technique and encourages formation of copolymer networks with tailored physical-chemical properties through rapid transformation of liquid monomers into solid membranes.

In our previous work [15], the modification of polymer host was done using solvent-free UV-curing technique by copolymerizing ethyl methacrylate (EMA) with methyl methacrylate (MMA) monomer. The copolymer was then added with sodium iodide (NaI) for SPEs preparation. The SPEs were found to show reasonably good photoelectro- chemical conversion efficiency when applied in DSSC [16]. In present study, we have attempted to use bio-based monomer which is deproteinized natural rubber (DPNR) and magnesium iodide as salt for SPEs preparation in order to produce greener polymer electrolytes with acceptable conductivity. DPNR was chosen due to its good adhesive characteristic which is expected to enhance electrode-electrolytes contact in DSSC. The physicochemical properties of P(EMA-co-DPNR) based PEs were studied and the highest conducting SPE was used for DSSC fabrication. To the best of author's knowledge, the use of P(EMA-co-DPNR) copolymer as polymer host for SPEs especially for DSSC application has not yet been reported in the literature.

\section{METHODOLOGY}

\subsection{Synthesis of P(EMA-co-DPNR)}

With the aim of producing a new copolymer, EMA (in liquid form) and DPNR (in solid form supplied by Rubber Research Institute, Malaysia) were copolymerized in the presence of a photo-initiator (DMPA) of a ratio of 1: 0.016 . The mixture was stirred until the DMPA completely dissolved and exposed to a UV radiation box of 15W UV lamps under a continuous flow of nitrogen gas for $30 \mathrm{~min}$. This preparation technique was reported in the authors' earlier article [16]. The copolymer formed was then washed using methanol in order to remove residual monomers.

\subsection{Preparation of Polymer Electrolyte Films}

Different weight percentages of $\mathrm{MgI}_{2}(0,5,10,15,20,25$, and 30) wt. \% was added to the solution of one grams of P(EMA-co-DPNR) in THF in separate beakers. The mixtures of the copolymer and magnesium salt were stirred using magnetic stirrers for $24 \mathrm{~h}$ at $40{ }^{\circ} \mathrm{C}$. The homogenous solutions of the electrolytes were then poured into glass 


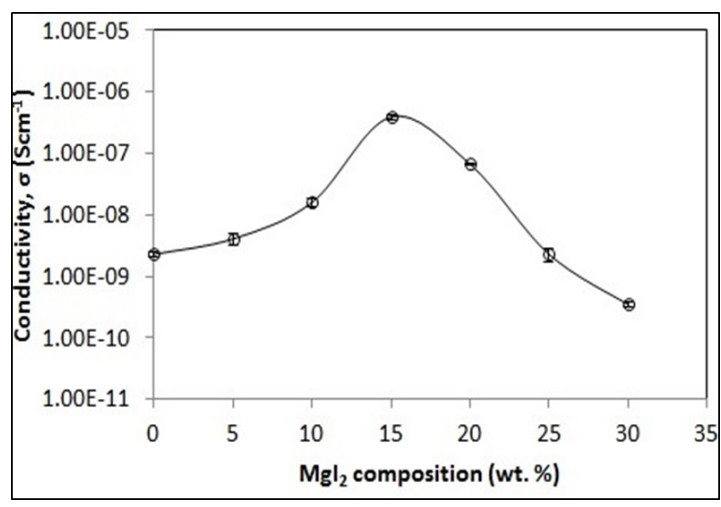

Fig. 1. Room temperature conductivity of P(EMA-co-DPNR) incorporated with different compositions of $\mathrm{MgI}_{2}$

petri dishes and allowed to evaporate slowly at room temperature to form films. The free standing films formed were peeled off from the glass petri dishes before being subjected to characterizations. The weight of P(EMA-co-DPNR) was used as a reference weight. Table 1 gives the details of compositions of the prepared SPE samples and their designations.

\subsection{Sample Characterization}

The ionic conductivity values of the SPE films were evaluated by impedance spectroscopic technique using a SOLARTRON $1260 \mathrm{im}$ pedance analyzer over a frequency range from $100 \mathrm{~Hz}$ to $5 \mathrm{MHz}$ with 100-mV DC potential amplitude. Each studied sample was sandwiched between stainless steel blocking electrodes and the impedance data were recorded at room temperature. Fourier transform infrared (FTIR) spectroscopy was carried out on all samples using the Perkin Elmer (Waltham, MA, USA) Frontier FTIR spectrometer in the wavenumber range from 550 to $4000 \mathrm{~cm}^{-1}$, with a scanning resolution of $1 \mathrm{~cm}^{-1}$ at room temperature. The thermogravimetric analysis was performed using a Labsys Evo-Setaram Instrument in nitrogen atmosphere from room temperature to $600{ }^{\circ} \mathrm{C}$ at heating rate of $10^{\circ} \mathrm{C} \mathrm{min}{ }^{-1}$. A sample of $\sim 15 \mathrm{mg}$ in the form of solid film was used to determine the weight loss with temperature of samples. The ionic transference number measurement was characterized using a direct current (d.c) polarization technique with an applied voltage of $2.5 \mathrm{~V}$ using stainless steel blocking electrode. Meanwhile, for magnesium-ion transference number $\left(T_{\mathrm{Mg}}{ }^{2+}\right)$ measurement, it was determined using Bruce and Vincent method [31] with non-blocking (magnesium metal) electrodes and was calculated according to the equation below:

$$
t^{+}=\frac{I_{\mathrm{s}}\left(\Delta V-R_{0} I_{0}\right)}{I_{0}\left(\Delta V-R_{\mathrm{s}} I_{\mathrm{s}}\right)}
$$

where $I_{0}$ and $I_{\mathrm{s}}$ are initial current and steady state current, respectively. $R_{0}$ and $R_{\mathrm{s}}$ are cell resistances before and after the polarization, re-

Table 1. P(EMA-co-DPNR)-MgI $\mathrm{M}_{2}$ SPE films prepared in this study.

\begin{tabular}{cccc}
\hline $\begin{array}{c}\text { P(EMA-co-DPNR) } \\
(\mathrm{g})\end{array}$ & $\begin{array}{c}\mathrm{MgI}_{2} \\
(\mathrm{~g})\end{array}$ & $\begin{array}{c}\mathrm{P}(\text { EMA-co-DPNR): } \\
\mathrm{MgI}_{2} \\
\text { (wt. \%: } \mathrm{wt} . \%)\end{array}$ & Designation \\
1.0 & 0 & $100: 0$ & $\mathrm{~A} 0$ \\
1.0 & 0.05 & $95: 5$ & $\mathrm{~A} 5$ \\
1.0 & 0.11 & $90: 10$ & $\mathrm{~A} 10$ \\
1.0 & 0.18 & $85: 15$ & $\mathrm{~A} 15$ \\
1.0 & 0.25 & $80: 20$ & $\mathrm{~A} 20$ \\
1.0 & 0.33 & $75: 25$ & $\mathrm{~A} 25$ \\
1.0 & 0.43 & $70: 30$ & $\mathrm{~A} 30$ \\
\hline
\end{tabular}

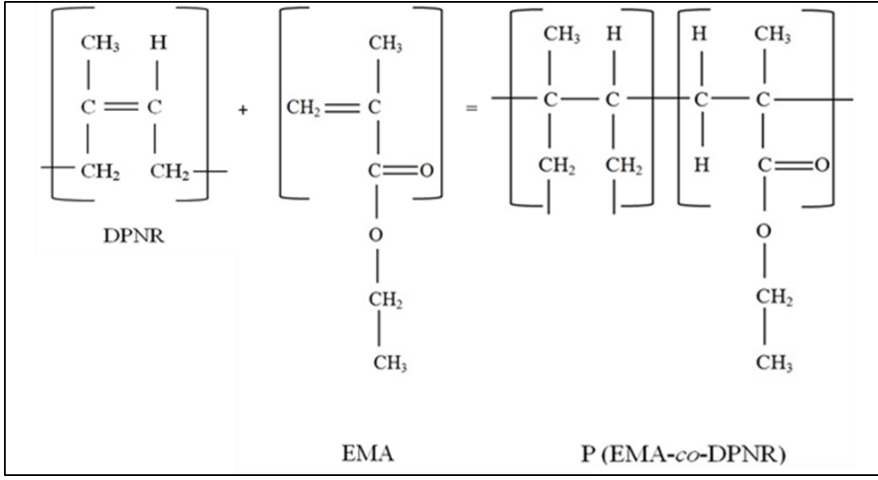

Fig. 2. Chemical structure of DPNR, EMA and P(EMA-co-DPNR)

spectively.

\subsection{Photoelectrochemical Cell Fabrication and Char- acterization}

For preparing working electrode (WE), FTO substrate was spread with $\mathrm{TiO}_{2}$ paste using the doctor blade technique. Then, the WE was annealed at $450{ }^{\circ} \mathrm{C}$ for $12 \mathrm{~h}$ in order to transform the $\mathrm{TiO}_{2}$ from the anatase phase into the rutile phase. The WE was then soaked in $0.3 \mathrm{mM}$ of N-719 dye solution at room temperature for $24 \mathrm{~h}$ for sufficient dye adsorption. A platinized FTO counter electrode (CE) was prepared separately by the brushing-painting technique and annealed at $450{ }^{\circ} \mathrm{C}$ for $12 \mathrm{~h}$ to activate the quasi-transparent platinum layer. The P(EMAco-DPNR)- $\mathrm{MgI}_{2}$ solution with the highest ionic conductivity was added with iodine $\left(\mathrm{I}_{2}\right)$ at a molar ratio of $10: 1$, cast onto the $\mathrm{TiO}_{2}$ photoanode $\mathrm{WE}$ and left to dry at room temperature before putting CE on top of it. The current-voltage $(I-V)$ data of the $\mathrm{FTO} / \mathrm{TiO}_{2}$-dye/A15/ $/ 2 / \mathrm{Pt} \mathrm{DSSC}$ were recorded using Zive Smart Manager software version 5.0.0.5. The DSSC was exposed to a xenon light source, at room temperature (dark atmosphere) and under AM (air mass) with 1.5 illumination at a light intensity of $100 \mathrm{~mW} \mathrm{~cm}^{-2}$ controlled by a radiometer. The illumination cell area was set to $1 \mathrm{~cm}^{2}$. The photoelectric performance parameters, such as the fill factor, $F F$ and light-to-electricity energy conversion efficiency, $\eta$, were calculated using Equations (1) and (2), respectively:

$$
\begin{aligned}
& F F=\frac{V_{\max } \times J_{\max }}{V_{\mathrm{OC}} \times J_{\mathrm{SC}}} \\
& \mathrm{\eta}=\frac{V_{\mathrm{OC}} \times J_{\mathrm{Sc}} \times F F \times 100}{P_{\text {in }}}
\end{aligned}
$$

where $V_{\text {oc }}$ is the open circuit voltage $(\mathrm{V}), J_{\mathrm{sc}}$ is the short circuit current density $\left.(\mathrm{mA} \mathrm{cm})^{-2}\right), P_{\text {in }}$ is the incident light power density $(\mathrm{mW}$ $\mathrm{cm}^{-2}$ ), while $V_{\max }(\mathrm{V})$ and $\left.J_{\max }(\mathrm{mA} \mathrm{cm})^{-2}\right)$ are the voltage and the current density in the $J-V$ curves, respectively, at the point of maximum power output [17].

\section{RESULTS AND DISCUSSION}

\subsection{Composition Dependence of Ionic Conductivity}

The variation of ionic conductivity of SPEs with $\mathrm{MgI}_{2}$ composition is shown in Fig. 1. The ionic conductivity increases with salt concentration up to $15 \mathrm{wt} . \% \mathrm{MgI}_{2}$. This is due to the increasing number of free ions with the increase of salt concentration. On further increase in salt concentration, ionic conductivity is observed to decrease. This is attributed to the formation of ion aggregates [18], which reduced the free-ion number density. The concentration at maximum ionic conductivity was 15 wt. $\% \mathrm{MgI}_{2}$ with room temperature ionic conductivity of 

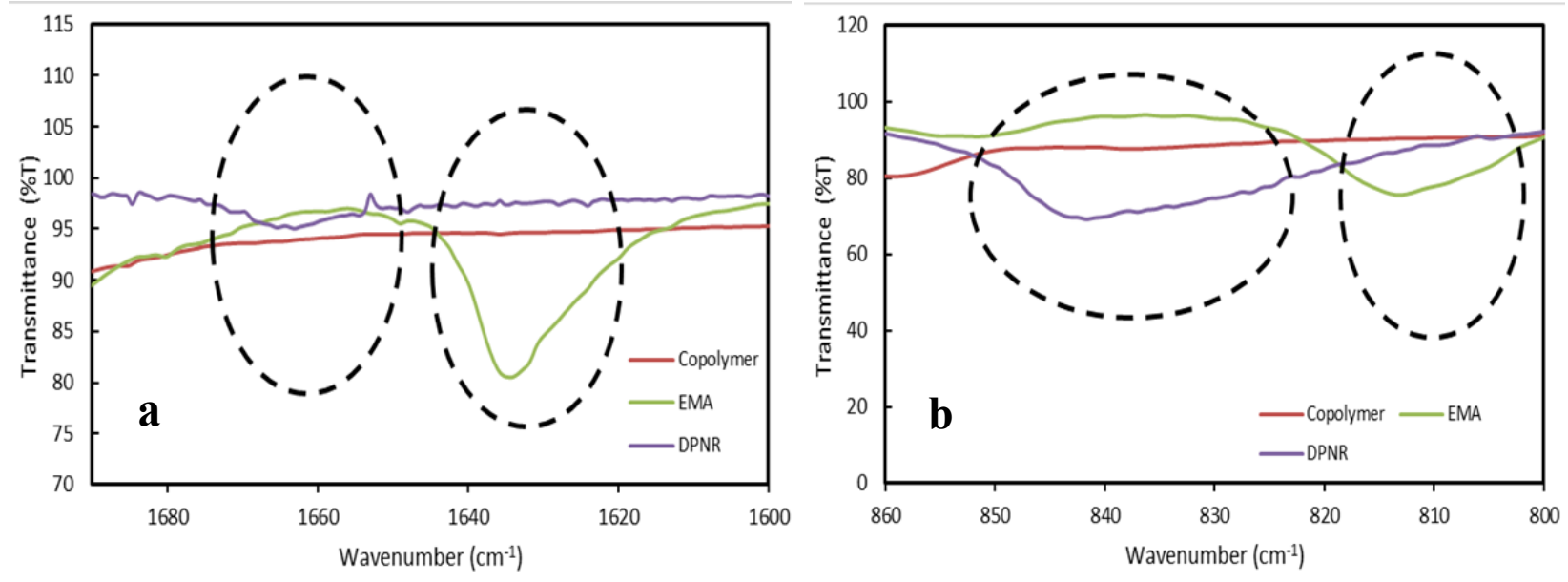

Fig. 3. ( $\mathrm{a}$ and $\mathrm{b})$ FTIR spectra in the region of vinyl group in EMA, DPNR and P(EMA - co - DPNR)
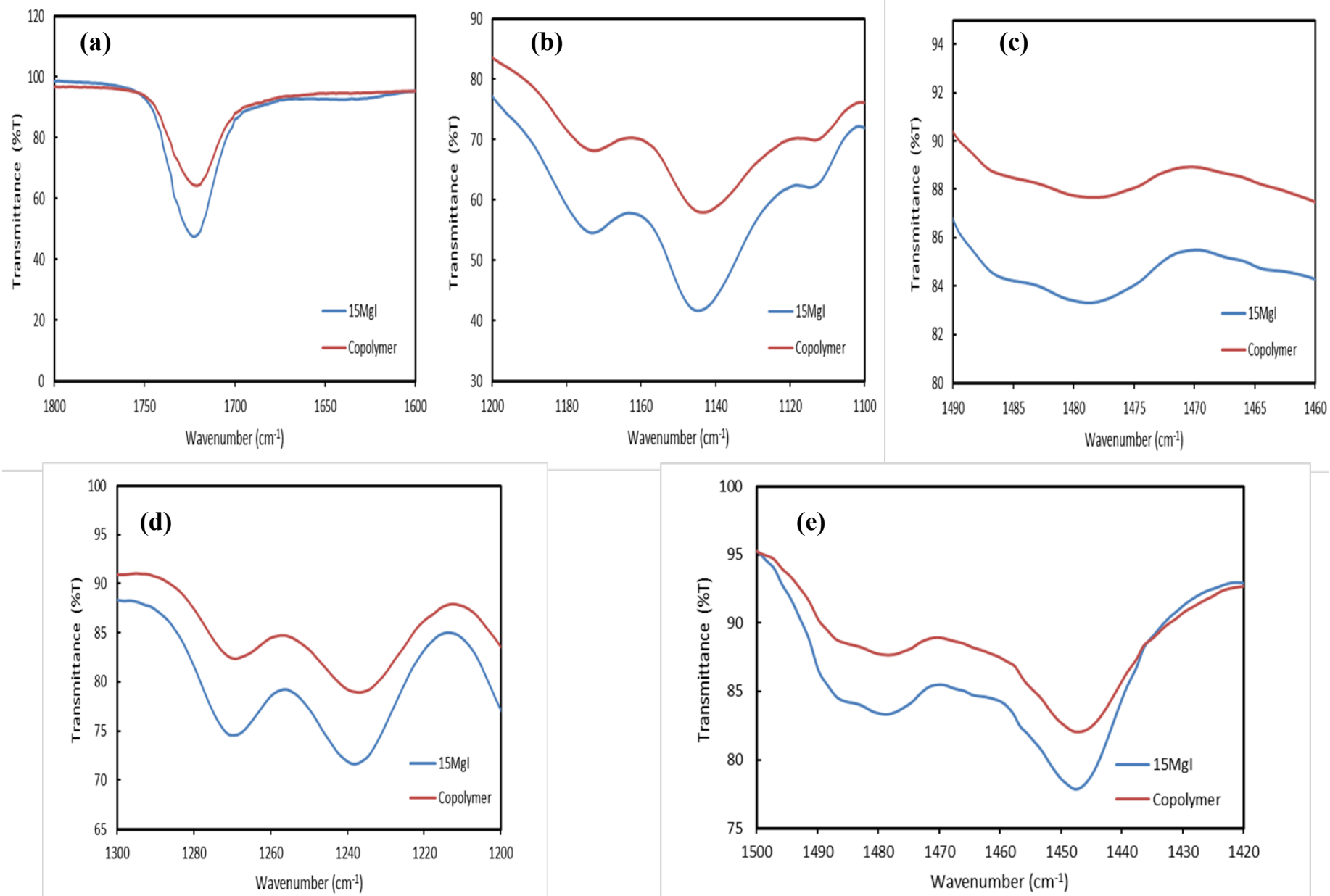

Fig. 4. (a-e) FTIR spectra of significant functional groups between host copolymer and P(EMA-co-DPNR)-MgI 2

\subsection{Fourier Transform Infrared Spectral Studies}

FTIR spectroscopy was employed to study the interactions between the components in the SPEs (i.e. P(EMA-co-DPNR) and $\mathrm{MgI}_{2}$ ). The chemical structure of EMA and DPNR before and after copolymerization is illustrated in Fig. 2. As can be seen in the figure, the $\mathrm{C}=\mathrm{C}$ bond will become single bond which is $\mathrm{C}-\mathrm{C}$ after the copolymerization occured. This indicates that the monomer and DPNR had participated in the reaction. This can be proven with FTIR spectra shown in Fig.3 (a and $b)$ where the stretching vibration band of $C=C\left(1637 \mathrm{~cm}^{-1}\right)$ group in EMA monomer and $\mathrm{C}=\mathrm{C}$ stretching $\left(1663 \mathrm{~cm}^{-1}\right),=\mathrm{C}-\mathrm{H}$ deformation 
$\left(810 \mathrm{~cm}^{-1}\right)$ in DPNR are disappeared.

In order to determine the bands belonging to P(EMA-co-DPNR) and the influences of $\mathrm{MgI}_{2}$ concentration to the polymer matrices, the IR spectra of $\mathrm{P}(\mathrm{EMA}-\mathrm{co}-\mathrm{DPNR})-\mathrm{MgI}_{2}$ were recorded for comparisons with pure $\mathrm{P}$ (EMA-co-DPNR) in the range of 550 to $4000 \mathrm{~cm}^{-1}$ as shown in Fig. 4. It could be observed that the FTIR spectra shows several important peaks assigned to $\mathrm{C}=\mathrm{O}$ stretching at $\left(1720-1731 \mathrm{~cm}^{-1}\right)$ (Fig. 4(a)) [16, 20], $v_{\mathrm{a}^{-}(\mathrm{C}-\mathrm{O}-\mathrm{C})}$ at $\left(1147-1151 \mathrm{~cm}^{-1}\right)$ (Fig. 4(b)) [20, 22] and $\mathrm{O}-\mathrm{C}_{2} \mathrm{H}_{5}$ at (1443-1451 cm $\mathrm{cm}^{-1}$ (Fig. 4(c)) [20, 21, 23, 24], $\mathrm{CH}_{2}$ scissoring at (1476-1479 $\mathrm{cm}^{-1}$ ) (Fig. 4(d)) [20, 22], $\mathrm{CH}_{2}$ twisting of DPNR at $\left(1200-1300 \mathrm{~cm}^{-1}\right)$ (Fig. 4(e)) [20],. From figures 4(a) until 4 (c), it can be seen that with addition of magnesium salt, the peaks of $\mathrm{C}=\mathrm{O}, v_{\mathrm{a}}-$ ${ }_{(\mathrm{C}-\mathrm{O}-\mathrm{C})}$ and $\mathrm{O}-\mathrm{C}_{2} \mathrm{H}_{5}$ are shifted to the higher wavenumbers more than 2 $\mathrm{cm}^{-1}$. The shifted of $\mathrm{C}=\mathrm{O}$ (from $1720 \mathrm{~cm}^{-1}$ to $1723 \mathrm{~cm}^{-1}$ ), $v_{\mathrm{a}}-(\mathrm{C}-\mathrm{O}-\mathrm{C})$ (from $1142 \mathrm{~cm}^{-1}$ to $1145 \mathrm{~cm}^{-1}$ ) and $\mathrm{O}_{-} \mathrm{C}_{2} \mathrm{H}_{5}$ (from $1445 \mathrm{~cm}^{-1}$ to 1448 $\mathrm{cm}^{-1}$ ) peaks to the higher wavenumber indicates that the weaker coordination of $\mathrm{Mg}$ ions onto the oxygen of these group. Since $\mathrm{Mg}$ ions are weakly coordinated to these groups, the cations are more labile and therefore can be transported more easily from one coordinating site to another, hence increased the ionic conductivity [25]. Besides that, peak of $\tau\left(\mathrm{CH}_{2}\right)$ twisting (Figures $4(\mathrm{~d})$ ) for DPNR at $1235 \mathrm{~cm}^{-1}$ is shifted to higher wavenumbers which is $1238 \mathrm{~cm}^{-1}$, as well as for ethyl group of EMA, $\mathrm{CH}_{2}$ scissoring $\delta\left(\mathrm{CH}_{2}\right)$ peak (Figure $4(\mathrm{e})$ ) at $1476 \mathrm{~cm}^{-1}$ shifted to $1479 \mathrm{~cm}^{-1}$. The shifted is may be due to the interaction with the anions $[26,27]$.

\subsection{Thermogravimetric Analysis}

Thermal stability of the SPEs is one of the key issues in practical application of DSSCs. In order to determine the thermal stability of the studied samples, TGA was performed. Fig. 5 shows the TGA profiles of the SPE samples. TGA curves show three weight loss regions for all samples in the temperature range of $30-600{ }^{\circ} \mathrm{C}$. Initial slight weight loss of $3-7 \%$ is in the temperature range of $55-100{ }^{\circ} \mathrm{C}$ which may due to the evaporation of the low molecular weight substance such as absorbed moisture and minor impurities.

Meanwhile, the mass loss occurred at the range of $100-180{ }^{\circ} \mathrm{C}$ is attributed to the evaporation of the residual solvent (THF) presence in the samples. This vaporization trend was also observed and reported previously by other researchers. [21, 28-29].

On the other hand, beyond $\sim 180^{\circ} \mathrm{C}$, all samples show two significant weight loss regions with degradation temperatures denoted as $T_{\mathrm{d} 1}=180$ ${ }^{\circ} \mathrm{C}$ and $T_{\mathrm{d} 2}=300{ }^{\circ} \mathrm{C}$. The $T_{\mathrm{d} 1}$ values decrease initially upon addition of $\mathrm{MgI}_{2}$ salts but only with small percentage weight loss $(\sim 15 \%)$ compared to A0 $(\sim 40 \%)$. This implies that the addition of the $\mathrm{MgI}_{2}$ improves the thermal stability of the P(EMA-co-DPNR) region of the copolymer.

In contrast, $T_{\mathrm{d} 2}$ is observed to decrease abruptly after the addition of $\mathrm{MgI}_{2}(\sim 65 \%)$ compared to sample A0 ( $\left.45 \%\right)$. This is possibly due to the overlapping of the weight loss of P(EMA-co-DPNR) and the degradation of $\mathrm{MgI}_{2}$ in the polymer matrices, which could be clearly observed in the thermograms for the samples incorporated with different amounts of $\mathrm{MgI}_{2}$ (A5, A15 and A30).

The TGA results indicate that thermal stability of the SPEs decreases upon addition of $\mathrm{MgI}_{2}$ salts with the mass loss (18 to $\left.22 \%\right)$ for A5, A 15 and A30 compared to A0, the mass loss $~ 14 \%$ in the region below $T_{\mathrm{d} 1}$. This phenomenon possibly due to less amount of energy required to break the interactive bond between copolymer and salts. The complexation between salts and copolymer has been confirmed from FTIR analysis discussion. Nevertheless, the mass loss at $50^{\circ} \mathrm{C}$ is negligible for all samples indicating that the SPEs are stable at that temperature. This thermal property is important to be considered for the potential electrolytes in DSSCs since the previous reports show that the best operating temperature for DSSCs is around $40{ }^{\circ} \mathrm{C}$ [28-29].

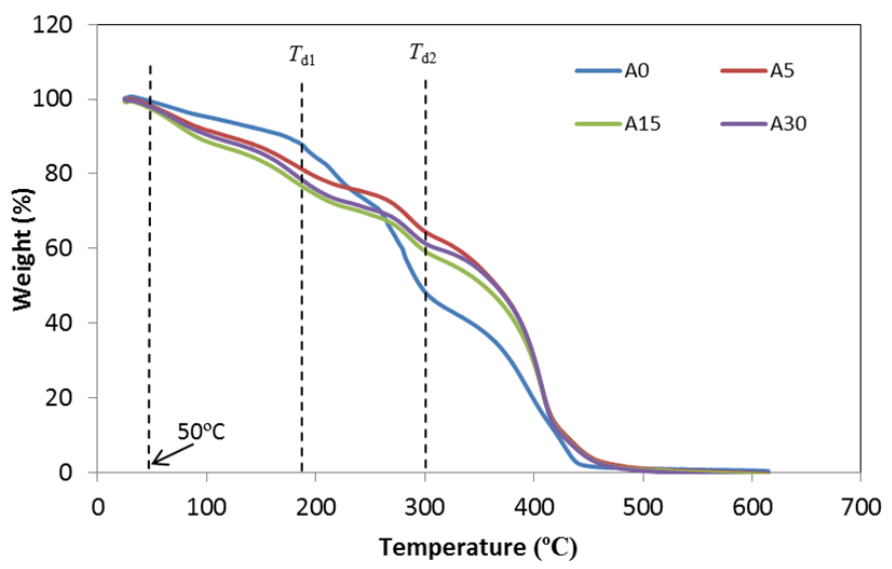

Fig. 5. TGA thermograms in the heating run for A0, A5, A15, and A30

\subsection{Transference Number Measurement}

From the normalized current versus time plot for A15 sample, the total ionic transference number was calculated using the equations below:

$$
\begin{aligned}
& t_{e}=\frac{I_{S s}}{I_{t}} \\
& t_{\text {ion }}=1-\frac{I_{S S}}{I_{\mathrm{t}}}
\end{aligned}
$$

where $I_{\mathrm{t}}$ is the total current at the start of the time and $I_{\mathrm{ss}}$ is the steady state current. The calculated ionic transference number, $t_{\text {ion }}$ is 0.93 which suggesting that the majority of charge carriers in this system are mainly due to ions.

Therefore, in the system of $\mathrm{MgI}_{2}$ incorporated P(EMA-co-DPNR) complexes, two types of charge carriers; namely $\mathrm{Mg}^{2+}$, and $\mathrm{I}^{-}$are expected to conduct. However, from Table 2, the value of $T_{\mathrm{Mg}}{ }^{2+}$ is found to be 0.04 at room temperature. This shows that the majority of ions transport in the electrolytes system was due to iodide anions. The presence of iodide anions in the polymer electrolytes system has been showed in the FTIR results earlier. The iodide anions are important for redox mediator in DSSC application.

\subsection{Photovoltaic Performances of DSSCs}

The photocurrent density-voltage $(J-V)$ curve for DSSC employing A15 SPE under irradiation of $100 \mathrm{~mW} \mathrm{~cm}{ }^{-2}$ is presented in Fig. 6. The values of the open-circuit voltage $\left(V_{\mathrm{oc}}\right)$, short-circuit current density $\left(J_{\text {sc }}\right)$, fill factor $(F F)$ and conversion efficiency $(\eta)$ are $0.54 \mathrm{~V}, 2.48 \mathrm{~mA}$ $\mathrm{cm}^{-2}, 0.40$ and $0.54 \%$, respectively. The result obtained demonstrates that $\mathrm{P}$ (EMA-co-DPNR)- $\mathrm{MgI}_{2}$ has potential to be further explored for application in DSSCs.

\section{CONCLUSIONS}

SPEs using a new P(EMA-co-DPNR) copolymer added with different amounts of $\mathrm{MgI}_{2}$ as doping salt were successfully prepared. FTIR

Table 2. The value of $\mathrm{Mg}|\mathrm{A} 15| \mathrm{Mg}$ cell during transference number measurement

\begin{tabular}{cccccc}
\hline Sample & $I_{\mathrm{o}}(\mathrm{A})$ & $I_{\mathrm{s}}(\mathrm{A})$ & $R_{\mathrm{o}}(\Omega)$ & $R_{\mathrm{S}}(\Omega)$ & $T_{\mathrm{Mg}}{ }^{2+}$ \\
\hline $\mathrm{A} 15$ & $1.09 \times 10^{-4}$ & $4.36 \times 10^{-6}$ & 3108 & 11114 & 0.04 \\
\hline
\end{tabular}




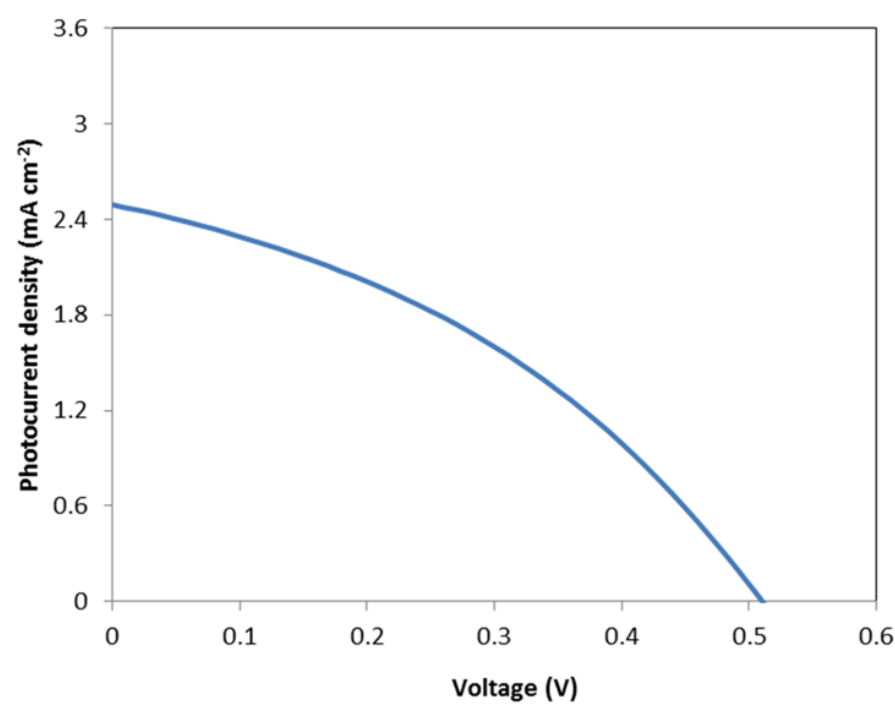

Fig. 6. $J-V$ curves of the dye-sensitized solar cell assembled using A15 SPE

spectra showed that the EMA and DPNR monomer were successfully copolymerized and the crystallinity of the copolymer decreased with addition of $15 \mathrm{wt} \%$ of $\mathrm{MgI}$, hence increased the ionic conductivity. The transference number measurements confirmed that the charge transport in the SPEs was predominantly due to iodide anions. Iodide anions are important for redox mediator in DSSCs. TGA studies confirmed that the SPEs were thermally stable for DSSCs. The photovoltaic performance of P(EMA-co-DPNR) based DSSCs indicated that the SPEs have potential to be further explored for application in DSSCs.

\section{ACKNOWLEDGEMENT}

This work was supported by the University of Malaya Research Grant, RP013B-13AFR.

\section{REFERENCES}

[1] O’Regan B, Grätzel M, Nature, 353, 737 (1991).

[2] Mathew S, Yella A, Gao P, Humphry-Baker R, Curchod BF, Ashari-Astani N, Tavernelli I, Rothlisberger U, Nazeeruddin MK, Grätzel M, Nature Chem., 6, 242 (2014).

[3] Gerosa M, Sacco A, Scalia A, Bella F, Chiodoni A, Quaglio M, Tresso E, Bianco S, IEEE Journal of Photovoltaics, 6, 498 (2016).

[4] Sommeling PM, Späth M, Smit HJP, Bakker NJ, Kroon JM, J. Photochem. Photobiol. A Chem., 164, 137 (2004).

[5] Meng QB, Takahashi K, Zhang XT, Sutanto I, Rao TN, Sato O, Fujishima A, Watanabe H, Nakamori T, Uragami M, Langmuir, 19, 3572 (2003).

[6] Theerthagiri J, Senthil RA, Madhavan J, Arof M, Kariem A., J. Appl. Polym. Sci., 132, 42489 (2015).

[7] Yang Y, Zhang J, Zhou C, Wu S, Xu S, Liu W, Han H, Chen B, Zhao XZ, J. Phys. Chem. B., 112, 6594 (2008).

[8] Nishimoto A, Watanabe M, Ikeda Y, Kohjiya S, Electrochim. Acta, 43, 1177 (1998).

[9] Ramesh S, Arof AK, Mat. Sci. Eng. B-Solid, 85, 11 (2001).

[10]Wiberg J, Marinado T, Hagberg DP, Sun L, Hagfeldt A, Albinsson B, J. Phys. Chem. C, 113, 3881 (2009).

[11]Wang Y, Sol Energ. Mat. Sol Cells, 93, 1167 (2009).

[12]Bella F, Lamberti A, Sacco A, Bianco S, Chiodoni A, Bongiovanni
R, J. Membrane Sci., 470, 125 (2014).

[13]Bella F, Ozzello ED, Sacco A, Bianco S, Bongiovanni R, Int. J. Hydrogen Energ., 39, 3036 (2014).

[14]Bella F, Sacco A, Salvador GP, Bianco S, Tresso E, Pirri CF, Bongiovanni R, J. Phys. Chem. C, 117, 20421 (2013).

[15]Dzulkurnain NA, Hanifah SA, Ahmad A, Mohamed NS, Int. J. Electrochem. Sci., 10, 84 (2015).

[16]Dzulkurnain NA, Ahmad A, Mohamed NS, Polymers, 7, 266 (2015).

[17]Bruce PG, Vincent CA, J. Electroanal Chem Interfacial Electrochem, 225, 1 (1987).

[18]Bella F, Ozzello ED, Bianco S, Bongiovanni R, Chem. Eng. J. 22, 873 (2013).

[19]Dissanayake MAKL, Sri Lankan Journal of Physics, 7, 1 (2006).

[20]Sim LN, Majid SR, Arof AK, Vib. Spectrosc., 58, 57 (2012).

[21]Rajendran S, Prabhu MR, Rani MU, J. Power Sources, 180, 880 (2008).

[22]Zain NF, Zainal N, Mohamed NS, Phys. Scripta, 90, 015702 (2014).

[23]Zain NF, Zainal N, Mohamed NS, Sci. Adv. Mater, 8, 1195 (2016).

[24]Fahmy T, Ahmed MT, Polym Test, 20, 477 (2001).

[25]Yap, K. S., Characteristics of PMMA-grafted natural rubber polymer electrolytes, Doctoral dissertation, University of Malaya (2012).

[26]Wang, W., Guo, X., \& Yang, Y., Electrochimica Acta, 56(21), 7347 (2011).

[27]Dzulkurnain, N. A., Ahmad, A., \& Mohamed, N. S., Science of Advanced Materials, 8(1), 41 (2016).

[28]Yusoff SNHM, Har SL, Han CC, Hashifudin A, Kammer HW, Polymers Research Journal, 7, 159 (2013).

[29]Pradeepa P, Edwinraj S, Prabhu, Chinese Chem Lett., 26, 1191 (2015).

[30]Sil A, Sharma R, Ray S, Surf Coat Tech, 271, 201 (2015).

[31]Berginc M, Krašovec UO, Jankovec M, Topič M., Sol Energ Mat Sol C, 91, 821 (2007).

[32]Raga SR, Fabregat-Santiago F, Phys Chem Chem Phys, 15, 2328 (2013).

[33]Evans J, Vincent CA, Bruce PG, Polymer, 28, 2324 (1987). 